\title{
Adult attachment, emotional control, and marital satisfaction
}

\author{
JUDITH A. FEENEY \\ University of Queensland, Australia
}

\begin{abstract}
This study extends previous research into the relations among attachment style, emotional experience, and emotional control. Questionnaire measures of these variables were completed by a broad sample of 238 married couples. Continuous measures of attachment showed that insecure attachment (low Comfort with closeness; high Anxiety over relationships) was related to greater control of emotion, regardless of whether the emotion was partner-related or not. Insecure attachment was also associated with less frequent and intense positive emotion and with more frequent and intense negative emotion, although these links depended on context (partner-related or not), attachment dimension, and gender. Emotional control added to the prediction of marital satisfaction, after controlling for attachment dimensions; the most robust links with satisfaction were inverse relations with own control of positive emotion and with partner's control of negative emotion. The results are discussed in terms of attachment theory, affect regulation, and communication in marriage.
\end{abstract}

There is substantial support for Hazan and Shaver's (1987) proposition that attachment theory can be usefully applied to romantic relationships. Measures of adult attachment style have been related to the quality of romantic relationships, as assessed by selfreport questionnaires (Collins \& Read, 1990; Kirkpatrick \& Davis, 1994), interview and diary-based reports (Feeney \& Noller, 1991; Feeney, Noller, \& Callan, 1994), behavioral ratings (Mikulincer \& Nachshon, 1991; Simpson, Rholes, \& Nelligan, 1992), and corroborative reports by partners (Kobak \& Hazan, 1991).

Much of this research is based on the premise that different attachment styles reflect differences in affect regulation-that is, ways of dealing with negative emotion. Through experiences with caregivers, individuals learn strategies for organizing emotional experience and handling attachment-

Address reprint requests to Judith A. Feeney, Department of Psychology, University of Queensland, Queensland 4072, Australia. E-mail: judy@psy.uq.edu.au. related distress, and these strategies generalize to other distressing situations (Sroufe \& Waters, 1977). Secure individuals, having experienced relatively warm and sensitive caregiving, tend to handle negative feelings constructively by acknowledging distress and seeking support. Avoidant individuals, having experienced insensitive or rejecting caregiving, tend to restrict expression of negative feelings in order to reduce conflict with attachment figures. Anxious-ambivalent individuals, by contrast, are thought to show heightened awareness and expression of negative feelings, learned as a way of maintaining contact with inconsistent caregivers (Kobak \& Sceery, 1988).

\section{Adult Attachment and Negative Emotion}

Researchers have used the concept of affect regulation to explain differences between adult attachment groups in responses to illness, fear, and loss, and in the processing of negative memories (Feeney \& Noller, 1992; Feeney \& Ryan, 1994; Mikulincer, Florian, \& Tolmacz, 1990; Mikulincer \& Orbach, 
1995). Further, the frequency of negative emotion in romantic relationships has been related inversely to secure attachment, and positively to avoidant and ambivalent attachment (Fuller \& Fincham, 1995; Simpson, 1990).

Laboratory studies directly assessing partners' responses to affect-laden situations also highlight the role of attachment style. Simpson et al. (1992) showed that when female partners were led to anticipate a stressful event, secure females' support-seeking and secure males' supportgiving increased with females' anxiety level; avoidant individuals, however, retreated from their partners when females' anxiety was high. Secure individuals show less negative affect than do others in response to partners' primed distancing behavior (Feeney, 1998), and ambivalent individuals become more distressed than do others during conflict interactions (Simpson, Rholes, \& Phillips, 1996).

These laboratory studies need to be integrated with more naturalistic research into the link between adult attachment and the expression or control of various negative emotions in intimate relationships. Verbal descriptions of responses to physical separation from dating partners suggest that subjects high in Anxiety over relationships (cf. anxious-ambivalence) are more likely than others to feel extreme negative emotion (despair, anger) during these times, but are less likely to discuss such feelings with their partners (Feeney, 1998). In another study of affect regulation in dating couples, participants rated their own and partner's responses to each of three negative emotions in their relationship: anger, sadness, and anxiety (Feeney, 1995). Insecure attachment (low Comfort with closeness, high Anxiety over relationships) was related to more frequent experience of negative affect in the relationship. Low Comfort with closeness was also related to reports of greater control ("bottling up") of all three emotions. Anxiety over relationships was related to greater control of anger, and to the perception that partners controlled their own sadness. Verbal reports of subjects' typical responses to the emotions also showed attachment differences, with secure respondents reporting more direct and open discussion of their emotion than other attachment groups.

These studies (Feeney, 1995, 1998) support Bowlby's assertion that anxiously attached children and adults will often fail to express their anger toward an attachment figure, for fear that expressions of hostility will drive the attachment figure away (Bowlby, 1973, pp. 250-256). This proposition is important to bear in mind, because some researchers into adult attachment have argued that anxious-ambivalence is marked by heightened expressions of anger and fear displayed directly toward attachment figures (e.g., Kobak \& Sceery, 1988, p. 136). Rather, it seems that ambivalent individuals (those high in Anxiety over relationships) may try to control or "bottle up" emotions such as anger so as not to place the relationship at risk. Further, the tendency for anxious-ambivalence to be linked to control of anger may be especially marked in the case of adult attachments. Unlike infant-caregiver attachments, the prototypical romantic bond involves reciprocal caregiving between peers; each partner relies on and supports the other (Hazan \& Shaver, 1994). Hence, it may be seen as less acceptable for adults to use extreme displays of distress to maintain contact with partners.

Clarifying the role of adult attachment in the control of emotion also requires consideration of how these variables impact on relationship quality. In another study of the sample reported by Feeney (1995), partner's control of emotion predicted relationship satisfaction, beyond that explained by own and partner's attachment dimensions: Satisfaction was related inversely to partner's control of sadness, but positively to partner's control of anger (Feeney, Noller, \& Roberts, 1998). Emotional control partly mediated the link between attachment and females' satisfaction; specifically, the lower satisfaction of females whose partners lacked Comfort with closeness was explained by the partners' bottling up of emotion. By con- 
trast, attachment and emotional control exerted independent effects on males' satisfaction. The prediction of satisfaction from emotional control, after statistically controlling for attachment, highlights the robust effect of emotional expressiveness on relationship quality (Noller \& Fitzpatrick, 1990); this effect is not surprising, given that affective processing is inextricably tied both to overt behavior and to cognitions about the partner and relationship (Bradbury \& Fincham, 1991).

\section{Adult Attachment and Positive Emotion}

The need to study the regulation of positive emotion is highlighted by the finding that satisfied couples not only handle negative emotions better than distressed couples, but also report much more positive interaction (Broderick \& O'Leary, 1986). Further, longterm happily married couples emphasize the role of positive affect in keeping their marriages satisfying (Osgarby \& Halford, 1996). Attachment theory has focused mainly on negative affect, but interactions with caregivers are also likely to influence the experience of positive affect and the strategies learned to deal with it. Indeed, expressions of positive affect are central to the concept of the attachment bond (Sroufe \& Waters, 1977). Moreover, infants' positive emotionality is linked to parents' involvement with the infant, and attachment security at 12 months relates more strongly to prior change in infants' positive emotionality than to change in their negative emotionality (Belsky, Fish, \& Isabella, 1991).

Among adults, avoidant and anxious/ambivalent attachment styles have been linked to less frequent experience of positive affect in intimate relationships (Simpson, 1990). Predictions can also be made about the implications of adult attachment for the control or expression of positive emotion, given individual differences in attachment-related attitudes and goals, and the importance of distance-regulation in adult attachments (Collins \& Read, 1994; Pistole, 1994). Because the expression of positive emotion is likely to lead to increased intimacy, indi- viduals who prefer to maintain distance from their partners (i.e., individuals who are avoidant, or low in Comfort with closeness) may tend to contain these emotions. In contrast, ambivalent individuals (those high in Anxiety over relationships) desire extreme closeness, but fear rejection and loss. Although the desire for extreme closeness suggests a tendency to express love and warmth, fears about loss and lack of reciprocation may lead ambivalent individuals to be cautious about expressing such feelings unless they are confident of their partners' response. Hence, Anxiety over relationships may show no systematic link with control of positive emotion.

In studying the link between adult attachment and the control of positive affect, a number of specific emotions should be assessed. First, happiness (or joy) is important, given widespread consensus that happiness is one of the "basic" emotions (Chance, 1980). Second, love is clearly relevant, because attachment theory deals with bonds of affection, and with individual differences in expressions of love and affection; in addition, love features prominently in laypersons' lists of emotions, and it satisfies most of the criteria used to define basic emotions (Shaver, Morgan, \& Wu, 1996). Third, pride is relevant to attachment research because it is a self-evaluative emotion (i.e., it involves evaluation of the self against some standard; Fischer \& Tangney, 1995). Caregivers play a key role in the development of self-evaluative emotions, by showing approval or disapproval of particular outcomes (Stipek, 1995). Moreover, like working models of attachment, pride is based on cognitive representations of self and other (Mascolo \& Fischer, 1995).

\section{The Present Study}

This study extends previous research relating attachment style to the experience and the control of particular emotions (Feeney, 1995). In addition to recruiting married (rather than dating) couples, the previous work was extended in four ways. First, consistent with the arguments made earlier, the 
focus was on positive emotions (happiness, love, and pride), as well as negative emotions (anger, sadness, and anxiety).

Second, to clarify any observed relations between attachment style and emotional control, measures of both the frequency and intensity of emotional experience were included. Feeney (1995) investigated the possibility that insecure individuals might report greater control of negative emotions than would secure individuals simply because they experienced such emotions more frequently. Her data did not support this interpretation, but the failure to control for the intensity of emotional experience was a limitation of that study.

Third, emotional experience and control were rated for each of two contexts. Specifically, participants rated how frequently and intensely they experienced each emotion when it was caused by "something the partner had done" (partner-related context), and when it was caused by "something not involving the partner" (other context); they also rated how much they controlled or contained each emotion from their partner, when the emotion was partner-related and when it was not. Attachment theory states that rules and strategies for regulating distress, learned with caregivers, generalize to other emotionally laden situations. Hence, attachment style should predict the tendency to contain (control) emotion from partners, whether the emotion is attributed directly to the partner or not. By contrast, the strength of the link between attachment and emotional experience may depend on the source of the emotion: Attachment measures tap thoughts and feelings about intimate bonds, and they tend to relate more strongly to emotional experience with intimate partners than to general emotionality (Shaver \& Brennan, 1992). One exception to this might be the link between anxiousambivalence and the pervasive experience of negative affect (Feeney \& Ryan, 1994).

Fourth, the implications of attachment dimensions and emotional control for relationship satisfaction were assessed. As noted earlier, Feeney et al. (1997) found that partner's control of negative emotion accounted for variance in relationship satisfaction, beyond that explained by attachment. There was also evidence that the link between attachment and satisfaction may be mediated, in part, by emotional control. There is a need to replicate and extend these findings to encompass the control of positive emotion.

Three hypotheses were derived from the literature reviewed above. For ease of presentation, the hypotheses are phrased in terms of attachment dimensions, although attachment style was also assessed. Given the limited research in this area, differential predictions were made for broad emotion type (positive, negative), but not for specific emotions. Similarly, differential predictions were not made for the effects of own and partner's attachment, although the latter effects may be weaker (Feeney, 1995).

Hypothesis 1 concerns the link between attachment and emotional control:

H1: Comfort with closeness was expected to be related inversely to the control of all types of emotion. Anxiety over relationships was expected to be related directly to the control of negative emotion (partnerrelated and other), but unrelated to the control of positive emotion.

Hypothesis 2 concerns attachment and emotional experience (frequency; intensity):

H2: Security of attachment (Comfort with closeness; low Anxiety over relationships) was expected to relate inversely to the experience of negative emotion and positively to the experience of positive emotion. Except for the link between Anxiety over relationships and experience of negative affect, these relations were expected to be strongest for partner-related emotions.

Hypothesis 3 concerns the predictors of marital satisfaction:

H3: Emotional control was expected to predict marital satisfaction, after own and 
partner's attachment dimensions were statistically controlled. Specifically, it was predicted that control of negative and positive emotions would be inversely related to satisfaction, although the possibility was explored that control of anger may not be detrimental to relationship quality.

\section{Method}

\section{Participants and procedure}

Participants were 238 married couples recruited by third-year psychology students as part of a class project. Students worked in pairs, with each pair asked to recruit four married couples from a range of sources (family, friends, colleagues). To maximize the reliability of the data, teaching assistants met with groups of students to discuss the process of data collection and to deal with any problems. A telephone contact was also provided to the couples so that any queries about the project could be addressed by the researcher. This type of sampling procedure has been shown to provide data that are fairly representative of the population at large (e.g., Noller, Law, \& Comrey, 1987).

A covering letter to couples explained the purpose and confidential nature of the project, and it emphasized the importance of each spouse completing the items independently. The order of instruments within the questionnaire package was counterbalanced. Couples returned the completed questionnaires to the researcher directly by mail, or via the student who recruited them. Sixty-eight couples who were approached by students declined to participate (a response rate of $77.8 \%$ ).

The sample represented a broad range of educational and occupational backgrounds. Although $60 \%$ of husbands and $58 \%$ of wives had some tertiary education, roughly one quarter $(24 \%$ of husbands, $28 \%$ of wives) had completed high school only, and the remainder had not completed schooling. A minority of the sample ( $9 \%$ of husbands, $30 \%$ of wives) were students or homemakers; $47 \%$ of husbands and $33 \%$ of wives held managerial or professional positions, and the remainder were evenly spread across manual and clerical occupations. Length of marriage ranged from 1 to 52 years, with a mean of 11.37 and a median of 10 years.

\section{Measures}

Attachment. To provide comprehensive assessment of current attachment, two measures were employed. First, attachment style was assessed by asking participants to endorse one of the four attachment descriptions developed by Bartholomew and Horowitz (1991): secure, preoccupied, dismissing, and fearful.

Second, participants completed a 13-item measure (Feeney et al., 1994), which yields scores on the two major dimensions underlying attachment style: Comfort with closeness (referred to as Comfort); and Anxiety over relationships (referred to as Anxiety). These two scales have been reported independently by other researchers (Simpson, 1990; Strahan, 1991). Sample items for the Comfort scale (8 items) include "I find it relatively easy to get close to others" and "I find it difficult to depend on others" (reverse-scored). Items for the Anxiety scale ( 5 items) include "I often worry that my partner doesn't really love me" and "I don't often worry about being abandoned" (reverse-scored). The items employ a 5-point response format, from $1=$ not at all like me, to $5=$ very much like me. Alpha reliability coefficients for the present sample were .78 (Comfort) and 87 (Anxiety).

Emotional control. Twelve 2-item scales assessed the reported control of emotion within the marriage. Specifically, participants rated the extent to which they controlled each of three negative emotions (anger, sadness, and anxiety) and three positive emotions (happiness, love, and pride). For each emotion, control was assessed for the two contexts described earlier: partnerrelated (when the emotion was caused by something the partner had done), and other (when it was caused by something not involving the partner). In each of the 12 scales, one item measured the extent to which participants "bottled up the feeling and kept it 
from the partner"; the other measured the extent to which they "openly expressed the feeling to the partner" (reverse-scored). The items were based on those developed by Watson and Greer (1983) and revised by Feeney (1995), and were answered on 5point scales, from $1=$ never, to $5=$ always. Hence, scores for each scale could range from 2 to 10, with higher scores indicating greater control or containment. Alpha coefficients for these scales all exceeded 73 .

Emotional experience. To assist interpretation of findings concerning emotional control, two additional items were included for each combination of emotion and context. The first item asked respondents to rate the frequency with which they experienced the particular emotion in the particular context (either because of "something your partner has done" or because of "something not involving your partner"), using a 5-point scale from $1=$ never or hardly ever, to $5=\mathrm{ex}$ tremely often. The second item required them to rate the "usual" intensity with which they experienced the particular emotion in the given context, on a 5-point scale from 1 $=$ not at all intense, to $5=$ extremely intense.

Marital satisfaction. Marital satisfaction was assessed using the Quality Marriage Index (Norton, 1983), a highly reliable scale comprising six items evaluating the overall relationship. Norton designed this measure using evaluative items because he argued that descriptive items (which describe aspects of communication, etc.) tend to create overlap with other variables of interest to the study of marriage. Internal consistency for the present sample was .95. Scores ranged from 8 to 42 , with a mean of 35.49 and a median of 37 ; the preponderance of relatively high scores is a typical finding in studies of married couples.

\section{Results}

\section{Overview of data analyses}

Three sets of analyses were used to address the research questions. First, correlations were calculated between own and partner's attachment dimensions and emotional control. Second, correlational analyses assessed relations between the attachment dimensions and emotional experience (frequency, intensity), and whether such relations account for the link between attachment and emotional control. Finally, using multiple regression analyses, attachment dimensions and emotional control were evaluated for their importance as predictors of marital satisfaction. It should be noted that the forced-choice measure of attachment was included to provide a more complete picture of participants' attachment styles, and to assess the convergence of findings concerning the correlates of emotional control across the different attachment measures. Given the strong overlap between the forced-choice and dimensional measures of attachment, results of analyses using the forced-choice measure are not presented in the text. ${ }^{1}$

\section{Attachment characteristics of the sample}

The numbers of husbands and wives endorsing each description of the forcedchoice measure of attachment style were: secure (123 and 133, respectively), preoccupied (27 and 39), dismissing (49 and 23), and fearful ( 37 and 41). There was a reliable link between attachment style and gender,

1. As would be expected, a preliminary MANOVA showed that the forced-choice measure of attachment style was strongly related to the attachment dimensions of Comfort and Anxiety. On the Comfort scale, highest scores were obtained by secure participants, and lowest scores were obtained by dismissing and fearful participants. On Anxiety, highest scores were obtained by preoccupied and fearful subjects, and lowest scores by secure participants. MANOVAs were also used to relate forcedchoice attachment style to control of negative and positive emotions. For negative emotions, the important distinction for both genders was between secure and fearful individuals, with the latter reporting more control. For positive emotions, avoidant individuals (fearful and dismissing) reported more control than did secure individuals. These attachment style differences were most pronounced for husbands' control of anger and sadness, and for wives' control of love and pride. 
$\chi^{2}(3)=12.17, p<.01$, with wives being more likely than husbands to endorse the preoccupied style, and less likely to endorse the dismissing style.

The two attachment scales were negatively intercorrelated $(r=-.31, p<.001)$, and showed substantial variability. Scores on Comfort ranged from 10 to $40(M=$ 28.30 , median $=29.00$ ), and scores on Anxiety ranged from 5 to $23(M=9.80$, median $=9.00)$.

\section{Attachment dimensions and emotional control}

Correlations were calculated between the attachment dimensions and reported control of each emotion in each context, separately for husbands and wives (see Table 1$){ }^{2}$ With regard to negative emotions (top half of Table 1), all associations with own attachment were significant for both husbands and wives, with insecure spouses (those low in Comfort and those high in Anxiety) reporting greater control. This link between own insecurity and the control of negative emotion supports Hypothesis 1.

For positive emotions, own lack of Comfort again correlated with greater reported control of each emotion, further supporting Hypothesis 1 . The link between own lack of Comfort and control of positive partner-related emotion was somewhat stronger for husbands than for wives (statistical testing revealed reliable differences between the correlations for husbands and wives for all three positive emotions). As expected, links

2. The fact that the correlational analyses reported in this article involve a large number of statistical tests raises questions concerning inflation of Type 1 error rate. However, it was decided for several reasons to retain the conventional alpha level of .05. First, the focal analyses relating attachment to emotional control clearly provided strong results; most of the correlations with own attachment were significant at .01 or beyond. Second, partialling the frequency and intensity of emotion from these correlations provided a more stringent test of the associations, but did not reduce their significance. Finally, for the remaining correlational analyses (frequency, intensity), half of the correlations (those not involving partner-related emotions) were not expected to be strong but were included for comparison purposes. between own Anxiety and control of positive emotions were less consistent, although both husbands and wives high in Anxiety reported greater control of love (partnerrelated and other).

In contrast to the predominant pattern of reliable associations between emotional control and own attachment, links with partner's attachment were more scattered. Respondents with spouses high in Anxiety tended to report greater control of negative emotions. Relations between partner's attachment and the control of positive emotions were limited mainly to wives: Wives with husbands high in Anxiety reported greater control of all positive emotions, and wives with husbands low in Comfort reported greater control of partner-related positive emotions.

As expected, the data in Table 1 suggest that the distinction between partner-related and other emotions was generally unimportant in terms of the link between attachment and emotional control. This point can be seen most clearly with regard to links with own attachment dimensions, given the greater number of significant results in this set. Of the 24 pairs of correlations between own attachment and emotional control, 19 were statistically significant for partnerrelated emotions, and 22 for "other" emotions. Further, statistical testing revealed only one reliable difference among the 24 pairs of correlations (partner-related vs. other): The link between wives' Anxiety and emotional control was stronger for partnerrelated than for "other" anger.

\section{Attachment dimensions and emotional experience}

Correlations were calculated between the attachment dimensions and reported experience of each emotion in each context, separately for husbands and wives. The correlations with frequency and intensity are presented in Tables 2 and 3, respectively.

Frequency. Own security of attachment (Comfort, low Anxiety) was related to reported frequency of all partner-related emo- 
Table 1. Correlations between own and partner's attachment dimensions and control of negative and positive emotions

\begin{tabular}{|c|c|c|c|c|c|c|c|c|}
\hline \multirow[b]{3}{*}{ Anger } & \multicolumn{2}{|c|}{ Comfort } & \multicolumn{2}{|c|}{ Anxiety } & \multicolumn{2}{|c|}{ Comfort } & \multicolumn{2}{|c|}{ Anxiety } \\
\hline & \multicolumn{4}{|c|}{ Partner-related } & \multicolumn{4}{|c|}{ Other } \\
\hline & $-.19 * *$ & .03 & $.24 * *$ & .01 & $-.22 * *$ & .07 & $.17^{* *}$ & .05 \\
\hline & $-.29 * *$ & -.08 & $.29 * *$ & $.19 * *$ & $-.17^{* *}$ & -.09 & $.16 *$ & .11 \\
\hline \multirow[t]{2}{*}{ Sadness } & $-.27 * *$ & -.02 & $.20 * *$ & $.15^{*}$ & $-.22 * *$ & -.04 & $.18^{* *}$ & $.24 * *$ \\
\hline & $-.24^{* *}$ & -.05 & $.18^{* *}$ & .13 & $-.22 * *$ & -.09 & $.18^{* * *}$ & $.23 * *$ \\
\hline \multirow[t]{2}{*}{ Anxiety } & $-.20 * *$ & .01 & $.23^{* *}$ & .07 & $-.26 * *$ & -.04 & $.15^{*}$ & $.17 * *$ \\
\hline &.$- \mathbf{3 1} * * *$ & -.08 & $.24^{* *}$ & $.23 * *$ & $-.22 * *$ & -.09 & $.26^{* *}$ & $.16^{*}$ \\
\hline \multirow[t]{2}{*}{ Happiness } & $-.36 * * *$ & -.04 & .12 & .12 & $-.28 * *$ & -.08 & .12 & .07 \\
\hline & $-.14^{*}$ & $-.15^{*}$ & .12 & $.14^{*}$ & $-.15^{*}$ & -.11 & .12 & $.16^{*}$ \\
\hline \multirow[t]{2}{*}{ Love } & $-.35 * * *$ & .03 & $.19 * *$ & .09 & $-.23^{* *}$ & -.06 & $.21 * *$ & $.16^{*}$ \\
\hline & $-.21 * *$ & $-.14 *$ & $.16^{*}$ & $.22 * *$ & $-.21 * *$ & -.11 & $.16^{*}$ & $.16^{*}$ \\
\hline \multirow[t]{2}{*}{ Pride } & $-.3^{*} * * *$ & .02 & .12 & .09 & $-.31 * * *$ & -.09 & $.29 * *$ & $.15^{*}$ \\
\hline & -.12 & $-.14^{*}$ & .12 & $.17^{* *}$ & $-.17 * *$ & -.10 & $.20 * *$ & $.16^{*}$ \\
\hline
\end{tabular}

Note: In each cell, the top entry is for husbands and the bottom entry is for wives; numbers in boldface are correlations with own attachment, and those in light face are correlations with partner's attachment.

${ }^{*} p<.05{ }^{* *} p<.01{ }^{* * *} p<.001$.

tions, for both husbands and wives. Specifically, security was associated with less frequent partner-related negative emotions, and more frequent partner-related positive emotions. These pervasive links between attachment security and emotional experience with intimate partners support $\mathrm{Hy}$ pothesis 2.
By contrast, relations between own attachment and frequency of emotions not attributed to the partner were generally restricted to the Anxiety dimension of attachment and to negative emotions: As predicted, Anxiety was associated with more frequent negative emotion, regardless of context. The only other significant findings

Table 2. Correlations between own and partner's attachment dimensions and frequency of experiencing negative and positive emotions

\begin{tabular}{|c|c|c|c|c|c|c|c|c|}
\hline \multirow[b]{3}{*}{ Anger } & \multicolumn{2}{|c|}{ Comfort } & \multicolumn{2}{|c|}{ Anxiety } & \multicolumn{2}{|c|}{ Comfort } & \multicolumn{2}{|c|}{ Anxiety } \\
\hline & \multicolumn{4}{|c|}{ Partner-related } & \multicolumn{4}{|c|}{ Other } \\
\hline & $-.16^{*}$ & -.12 & $.20^{* *}$ & $.26^{* *}$ & -.12 & .02 & $.17^{*}$ & .07 \\
\hline & $-.17 * *$ & -.09 & $.19 * *$ & .06 & -.04 & .02 & $.21^{* *}$ & -.06 \\
\hline \multirow{2}{*}{ Sadness } &.$- .13^{*}$ & -.07 & $.26 * *$ & $.20 * *$ & -.02 & -.04 & $.21^{* *}$ & .02 \\
\hline & $-.21 * *$ & $-.16^{*}$ & $.27^{* *}$ & .12 & .06 & -.02 & $.16^{*}$ & -.08 \\
\hline \multirow[t]{2}{*}{ Anxiety } & $-.23 * *$ & -.04 & $.22 * *$ & .11 & -.11 & -.02 & $.27 * *$ & .07 \\
\hline & $-.20 * *$ & -.05 &. $\mathbf{3 3}^{* * *}$ & $.16^{*}$ & .01 & -.04 & $.16^{*}$ & -.05 \\
\hline \multirow[t]{2}{*}{ Happiness } & $.29 * *$ & -.10 & $-.17^{*}$ & -.03 & .11 & -.05 & -.07 & .11 \\
\hline & $.15^{*}$ & $.15^{*}$ & $-.14^{*}$ & $-.23 * *$ & .12 & -.01 & -.12 & -.04 \\
\hline \multirow[t]{2}{*}{ Love } & $.24^{* *}$ & -.10 & $-.15^{*}$ & -.05 & .08 & -.05 & -.08 & .01 \\
\hline & $.25^{* *}$ & $.17^{*}$ & $-.16^{*}$ & $-.20 * *$ & .12 & -.05 & -.12 & -.08 \\
\hline \multirow[t]{2}{*}{ Pride } & $.19^{* *}$ & -.12 & $-.16^{*}$ & -.06 & $.15^{*}$ & -.08 & .01 & .06 \\
\hline & $.16^{*}$ & .04 & $-.13^{*}$ & $-.24 * *$ & .05 & -.11 & $-.14^{*}$ & -.12 \\
\hline
\end{tabular}

Note: In each cell, the top entry is for husbands; the bottom entry is for wives; numbers in boldface are correlations with own attachment, and those in light face are correlations with partner's attachment.

${ }^{*} p<.05{ }^{* *} p<.01 .{ }^{* * *} p<.001$. 
Table 3. Correlations between own and partner's attachment dimensions and intensity of experiencing negative and positive emotions

\begin{tabular}{|c|c|c|c|c|c|c|c|c|}
\hline \multirow{4}{*}{ Anger } & \multicolumn{2}{|c|}{ Comfort } & \multicolumn{2}{|c|}{ Anxiety } & \multicolumn{2}{|c|}{ Comfort } & \multicolumn{2}{|c|}{ Anxiety } \\
\hline & \multicolumn{4}{|c|}{ Partner-related } & \multicolumn{4}{|c|}{ Other } \\
\hline & -.12 & -.11 & $.25^{* *}$ & $.22 * *$ & -.08 & -.02 & .12 & -.02 \\
\hline & -.12 & -.06 & $.23^{* *}$ & .09 & -.03 & .10 & $.18 * *$ & -.04 \\
\hline \multirow[t]{2}{*}{ Sadness } & -.03 & -.05 & $.19^{* *}$ & .11 & -.12 & -.02 & $.13^{*}$ & .05 \\
\hline & -.05 & -.04 & $.21^{* *}$ & .02 & .06 & .06 & $.15^{*}$ & -.08 \\
\hline \multirow[t]{2}{*}{ Anxiety } & -.07 & -.03 & $.19^{* *}$ & .11 & -.01 & -.11 & $.17^{* *}$ & .07 \\
\hline & -.04 & .11 & $.28 * *$ & .09 & -.02 & .06 & $.13^{*}$ & .02 \\
\hline \multirow[t]{2}{*}{ Happiness } & $.22 * *$ & $.21 * *$ & -.04 & .05 & .09 & -.09 & -.05 & $.14 *$ \\
\hline & .02 & .04 & -.01 & $-.14^{*}$ & .10 & .11 & -.09 & -.06 \\
\hline \multirow[t]{2}{*}{ Love } & $.14 *$ & $.18^{* *}$ & .07 & -.01 & .07 & -.05 & .08 & -.03 \\
\hline & .12 & .10 & .01 & -.09 & .08 & .01 & -.06 & -.02 \\
\hline \multirow[t]{2}{*}{ Pride } & $.21 * *$ & $.17 * *$ & -.05 & .04 & $.16^{*}$ & -.08 & -.01 & .09 \\
\hline & .04 & .07 & -.04 & -.05 & .03 & .04 & -.05 & .01 \\
\hline
\end{tabular}

Note: In each cell, the top entry is for husbands; the bottom entry is for wives; numbers in boldface are correlations with own attachment, and those in light face are correlations with partner's attachment.

$* p<.05 . * * p<.01$.

for emotions not involving the spouse were relatively weak links between attachment dimensions and reported frequency of pride. Again, differences among the 24 pairs of correlations linking own attachment with frequency of emotion (partner-related vs. other) were tested statistically, and they showed 14 significant differences; in each case, the difference indicated stronger association for partner-related than for "other" emotions.

In addition, relations between partner's attachment and frequency of emotions were restricted completely to partnerrelated emotions. The most consistent findings in this set linked husbands' security (Comfort, low Anxiety) with wives' more frequent experience of partner-related positive emotions, although there were also scattered findings linking spouse's Anxiety with more frequent experience of partnerrelated negative emotions.

Intensity. The major finding for own attachment and intensity of emotion was that, as expected, spouses who were high in Anxiety reported more intense negative emotions (see Table 3 ). The only other consistent finding for own attachment was that, for husbands, Comfort was associated with greater intensity of partner-related positive emotions. Contrary to Hypothesis 2, there were no links between own Comfort and intensity of negative partner-related emotions, or between own Anxiety and intensity of partner-related positive emotions.

There was limited evidence that the link between own attachment and intensity of emotional experience may be stronger for emotions involving the partner. Differences among the 24 pairs of correlations (partnerrelated vs. other) were tested statistically and showed four significant differences, all in the expected direction. Further, of the nine reliable correlations between own attachment and intensity of partner-related emotions, four were significantly weaker in the case of "other" emotions.

Links between partner's attachment and intensity of emotional experience were most consistent for husbands' Comfort and wives' partner-related positive emotions. Wives whose husbands were high in Comfort reported greater intensity of all three partner-related positive emotions.

Linking emotional experience and emotional control. Correlations between attachment and reported emotional experience raise questions about interpretation of 
the link between attachment and emotional control. That is, the greater control reported by insecure spouses may merely reflect their greater frequency and intensity of experiencing emotions. To verify this possibility, the correlations between attachment dimensions and emotional control were recalculated, partialling out the reported frequency and intensity of the particular emotion. (These calculations were performed only for correlations with own attachment dimensions, given the more consistent findings within this set of results.)

The resulting partial correlations were almost identical to the zero-order correlations in Table 1 (for this reason, these results are not tabulated). Of the 41 significant correlations, only one became nonsignificant when frequency and intensity were controlled (wives' Comfort with control of partnerrelated love). Hence, the link between insecure attachment and emotional control cannot be explained in terms of attachmentrelated differences in the frequency and intensity of emotion.

\section{Predicting marital satisfaction}

Separate regression analyses were conducted for husbands and wives, predicting scores on the Quality Marriage Index. Own and partner's attachment dimensions were entered at Step 1, and reports of own and partner's control of negative and positive emotions were entered at Step 2.

To maintain an appropriate number of predictor variables in these analyses, emotional control was averaged over context (partner-related and other); separate analyses for emotional control in each context showed similar results to those for the averaged data. Also, in contrast to the work reported by Feeney et al. (1997), measures of total control of negative and positive emotions are reported, rather than separate measures for each specific emotion. Because the effect of emotional control on satisfaction may depend on the specific emotion, preliminary regression analyses were conducted in which own and partner's control of either the three negative emotions or the three positive emotions were entered at Step 2. The results did not add useful information to those using total scores, however, and the correlations between satisfaction and emotional control were similar for each specific emotion.

The results of the regression analyses appear in Table 4. Husbands' marital satisfaction was reliably predicted by own and

Table 4. Multiple regression analyses predicting marital satisfaction from own and partner's attachment dimensions and emotional control

\begin{tabular}{lrcrcc}
\hline & \multicolumn{2}{c}{ Husbands } & \multicolumn{2}{c}{ Wives } \\
\cline { 2 - 5 } Variable & $r$ & Beta & & $r$ & Beta \\
\hline Step 1 & .28 & $.20^{* *}$ & .31 & $.23^{* * *}$ \\
Own Comfort & -.42 & $-.35^{* * *}$ & -.29 & $-.16^{*}$ \\
Own Anxiety & .12 & .03 & .22 & .12 \\
Partner Comfort & -.23 & $-.14^{*}$ & -.36 & $-.30^{* * *}$ \\
Partner Anxiety & & & & $.20^{* *}$ \\
Step 2 & .28 & .03 & .31 & -.11 \\
Own Comfort & -.42 & $-.33^{* * *}$ & -.29 & -.01 \\
Own Anxiety & .12 & .09 & .22 & $-.22^{* *}$ \\
Partner Comfort & -.23 & $-.14^{*}$ & -.36 & $-.22^{* *}$ \\
Partner Anxiety & -.45 & $-.27^{* * *}$ & -.42 & $-.18^{*}$ \\
Own Control (Neg.) & -.39 & $-.17^{*}$ & -.44 & -.13 \\
Own Control (Pos.) & -.28 & $-.18^{*}$ & -.40 & -.32 & \\
Partner Control (Neg.) & -.18 & -.05 & & \\
Partner Control (Pos.) & & & & \\
\hline
\end{tabular}

Note: ${ }^{*} p<.05 .{ }^{* *} p<.01 .{ }^{* * *} p<001$. 
partner's attachment dimensions at Step 1, $R^{2}=.23, F(4,194)=14.69, p<.001$. Specifically, husbands' satisfaction was related negatively to own Anxiety and partner's Anxiety, and positively to own Comfort. Consistent with Hypothesis 3, the emotional control measures provided a reliable increase in explained variance $\left(R^{2}\right.$ for the full model $=.35, F$ (inc) $=8.68, p<.001$ ). Lower satisfaction was related to own control of negative and positive emotion and to partner's control of negative emotion, as well as to own and partner's Anxiety.

In the full model, the standardized regression weight for own Comfort was no longer significant. This finding suggests that the association between husbands' Comfort and their marital satisfaction is mediated by emotional control (that is, their tendency not to control or contain their emotion). The other requirements for this mediated relationship (Baron \& Kenny, 1986) have already been established: The regression analysis linked both the independent variable (attachment) and proposed mediator (emotional control) with satisfaction, and attachment was clearly linked to emotional control (Table 1).

Wives' marital satisfaction was also predicted by own and partner's attachment dimensions, $R^{2}=.25, F(4,194)=16.00, p<$ .001. As for husbands, wives' satisfaction was related inversely to own Anxiety and partner's Anxiety, and directly to own Comfort. Consistent with Hypothesis 3, addition of the emotional control measures again resulted in an increase in explained variance $\left(R^{2}\right.$ for the full model $=.38, F($ inc $)=10.76$, $p<.001$ ). In the full model, lower satisfaction was related to own control of positive emotion and partner's control of negative emotion, as well as to partner's Anxiety and own lack of Comfort.

To examine more fully the role of attachment and emotional control in predicting relationship satisfaction, the regression analyses were repeated, reversing the order of entry of the two sets of predictors (i.e., entering emotional control at Step 1, and attachment dimensions at Step 2). For both husbands and wives, the emotional control measures predicted satisfaction at Step 1 $\left(R^{2}=.18\right.$ for husbands and .24 for wives; $p$ $<.001$ in each case). For each gender, partner's control of positive emotion was the only variable with a nonsignificant regression weight. At Step 2, the attachment dimensions added to the prediction of satisfaction (again, $p<.001$ for each gender). Because the results for the full regression model are not affected by the order of entry of predictors, these results have not been tabulated.

\section{Discussion}

\section{Attachment characteristics of the sample}

The frequencies of spouses endorsing each description of the forced-choice measure are similar to those reported in previous samples of intact couples (e.g., Feeney, 1995). The tendency for wives to endorse the preoccupied style, and for husbands to endorse the dismissing style, is also consistent with previous research (Bartholomew \& Horowitz, 1991).

Scores on the attachment scales spanned almost the full possible range, although mean scores suggested that the sample tended to be relatively high in Comfort and low in Anxiety. The reliability and validity of responses to the attachment measures are supported by the meaningful pattern of relations between the forced-choice and continuous measures (the low Comfort reported by dismissing and fearful-avoidant individuals is consistent with their perception that others are uncaring and untrustworthy, and the high Anxiety reported by preoccupied and fearful individuals is consistent with their perception that they themselves are undeserving of love and attention).

\section{Attachment dimensions and emotional control}

Own security of attachment (high Comfort, low Anxiety) was associated with less reported control of all emotions assessed in this study. Although the results for the Com- 
fort dimension replicate those reported by Feeney (1995), the association between Anxiety and the control of negative emotion was less consistent in the earlier study, being strongest for anger. This different result may reflect differences between the two samples (dating vs. married couples). Anger is a potentially destructive emotion, and its expression is discouraged by social norms (Wallbott \& Scherer, 1988). Hence, it is possible that in dating relationships, which are less stable and committed than marital bonds, individuals high in Anxiety see anger as a particularly dangerous emotion to express; in later stages of relationship development, their concerns over the expression of anger may generalize to other negative emotions. This explanation suggests that although the strategies for dealing with attachment-related distress are thought to generalize to other emotionally laden situations in childhood, a similar process of generalization may also operate within the context of adult attachment relationships.

Certainly the present results do not support the proposition that, in marriage, Anxiety over relationships is associated with the exaggerated expression of attachmentrelated emotions. Rather, as noted earlier, adults who are highly anxious about relationship issues may try to avoid extreme displays of attachment-related distress, for fear of alienating relationship partners. Nevertheless, their anxiety may be manifested in a variety of behaviors, including relatively subtle responses such as verbal and nonverbal appeals (Feeney \& Noller, 1996). In the present study, Anxiety was linked not only with own emotional control but also with partner's emotional control. Partners of individuals high in Anxiety reported greater control of all the emotions assessed in this study, although some of these effects were specific to one gender or context.

As expected, the distinction between partner-related and other emotions was generally unimportant in terms of the link between attachment dimensions and emotional control. The only exception was the link between wives' Anxiety and their emotional control, which was stronger for partner-related than for "other" anger. Again, this finding may reflect the potentially destructive nature of expressions of anger, especially when that emotion is attributed directly to the relationship partner.

\section{Attachment dimensions and emotional experience}

Frequency. The pervasive links between own attachment security and the frequency of experiencing specific emotions concerning relationship partners are consistent with Hypothesis 2 . These links are also consistent with previous research relating attachment style to emotional experience within romantic relationships (Fuller \& Fincham, 1995; Simpson, 1990). Specifically, secure attachment (high Comfort, low Anxiety) was associated with more frequent positive emotion attributed to the partner, and less frequent negative emotion attributed to the partner.

In contrast, relations between own attachment and frequency of emotions not attributed to the partner were generally restricted to Anxiety being associated with more frequent negative emotion. The only other significant results for emotions not attributed to the partner involved the reported frequency of pride. Husbands' Comfort was related to more frequent pride, and wives' Anxiety was related to less frequent pride; although these associations were not strong, they are consistent with the argument that positive representations of self play an important role both in secure attachment and in appraisals of pride (Mascolo \& Fischer, 1995).

It should also be noted that links between partner's attachment and frequency of experiencing specific emotions were restricted almost entirely to wives' experience of emotions directly involving the partner. That is, husbands' attachment security appears to influence the frequency of wives' positive and negative affect toward their spouses. This finding may reflect wives' greater sensitivity to partners' feel- 
ings about issues such as intimacy, loss, and rejection. That is, wives may become aware of these issues and of the behaviors associated with partners' insecurity more often than husbands, and may react emotionally in accordance with this awareness. Although this explanation is speculative, it fits with reported sex differences in the accuracy of decoding spouses' nonverbal messages (Noller \& Gallois, 1988), and in sensitivity to spouses' needs for care and support (Feeney, 1996).

The fact that links between own and partner's attachment dimensions and frequency of emotion were primarily restricted to partner-related emotions is important, because it suggests that participants in this study responded to the measures in terms of experiences specific to close relationships, rather than in terms of a general response bias. The reliable links between Anxiety and the frequency of negative emotions not involving the partner were expected; theory and research suggest that those high in Anxiety develop a generalized hypervigilance to negative affect (Feeney \& Ryan, 1994), although such hypervigilance may stem primarily from concerns about potential abandonment or loss.

Intensity. As predicted, spouses high in Anxiety reported more intense negative emotions. In addition, husbands' Comfort was associated with greater intensity of partner-related positive emotions. There was evidence that the link between own attachment security and emotional intensity may be somewhat stronger for partnerrelated than for other emotions, with fewer than half of the reliable correlations with intensity of partner-related emotions holding up for other emotions.

Comfort was not related to intensity of negative partner-related emotions, and Anxiety was not related to intensity of positive partner-related emotions. These results were unexpected, and they offer preliminary evidence that own attachment is more predictive of the frequency of particular emotions, rather than of their intensity.
More specifically, Comfort predicted the frequency of all partner-related emotions, but predicted intensity of positive emotions only. Because the Comfort dimension of attachment taps thoughts and feelings about expressions of intimacy, it is understandable that Comfort is linked to the frequency and intensity of the related emotions of love, pride and happiness. Similarly, Anxiety predicted the frequency of all partner-related emotions, but predicted intensity of negative emotions only. Because the Anxiety dimension taps fears of loss and rejection, Anxiety may be more relevant to experiencing the related emotions of anxiety, sadness, and anger.

Effects of partner attachment on reported intensity of emotions were relatively weak. However, husbands whose wives were high in Anxiety reported more intense anger involving the partner, and husbands whose wives were low in Comfort reported less intense experience of all three positive emotions involving the partner. Hence, wives' Comfort appears to play a role in influencing the intensity of husbands' positive affect toward them. In the course of long-term relationships, men whose partners are comfortable with intimacy may develop deeper feelings of love and pride toward the partner, or may become more comfortable acknowledging such feelings. These effects may be restricted to men, for whom the traditional sex-role stereotype involves a relative lack of expressivity and nurturance. Further research is clearly needed to explore the mechanisms involved in these associations, which may involve modeling, and/or direct discussion of issues concerning intimacy.

The intensity data also suggest that participants in this study were describing attitudes and behaviors that are specific to close relationships, and that reflect strategies for dealing with attachment-related distress. (Links between attachment dimensions and intensity were largely restricted to negative emotions, and were somewhat stronger for partner-related than other emotions.) The fact that the attachment di- 
mensions showed rather different relations with frequency and with intensity of emotion was not expected, but this provides further evidence that participants did not simply respond in terms of a general response set.

Linking emotional experience and emotional control. As noted earlier, the correlations between attachment dimensions and emotional experience raise questions about the nature of the link between attachment and emotional control. That is, the greater control reported by insecure spouses may merely reflect their greater frequency and intensity of experiencing emotion. However, this possibility was not supported by the partial correlations between own attachment and emotional control, in which the reported frequency and intensity of emotion were statistically controlled. The partial correlations were atmost identical to the zero-order correlations, and hence the link between insecurity and emotional control appears to be independent of attachment-related differences in emotional experience.

\section{Predicting marital satisfaction}

For both husbands and wives, marital satisfaction was related negatively to own Anxiety and partner's Anxiety, and positively to own Comfort. Partner's Comfort did not predict satisfaction for either gender. These results are generally consistent with previous research, which suggests that relationship functioning is linked more strongly to own than to partners' attachment style, and that the most robust "partner" effect is a negative effect of women's Anxiety (Feeney \& Noller, 1996). Further, partner's Comfort may be more predictive of the quality of dating relationships (e.g., Collins \& Read, 1990) than of established marriages, in which issues concerning intimacy are likely to have been substantially negotiated (directly or indirectly).

The detrimental effect on marital satisfaction of partner's control of negative emotion, apparent for both husbands and wives, replicates the finding of Feeney et al. (1998). However, in contrast to the earlier study, the present study found that own control of negative emotion also strongly predicted husbands' lower satisfaction. The reason for the different results for men across the two studies is not clear. Perhaps in established marriages, husbands' own suppression of negative emotion is important because it signals a more general failure to relate to the spouse on an intimate level.

In predicting husbands' satisfaction, there was a substantial reduction from Step 1 to Step 2 in the regression weight for own Comfort. This result is the only reliable evidence of mediation effects in the present study, and it suggests that the link between husbands' Comfort and their marital satisfaction may be largely explained by the emotional expressiveness associated with comfort with intimacy. Feeney et al. (1998) also reported that emotional control mediated the association between husbands' Comfort and relationship satisfaction, although in that study, this link applied to the prediction of women's satisfaction.

At this stage, it is not clear why evidence of emotional control mediating the link between attachment style (Comfort) and satisfaction was limited to men. However, the association between own Comfort and the intensity of positive partner-related emotion was stronger for husbands than for wives, as was the association between own Comfort and the tendency not to control positive partner-related emotion. Hence, there may be gender differences in how lack of Comfort is manifested: In men, who have generally not been socialized to deal openly with emotions such as love and pride, low Comfort is likely to be manifested in less positive affect being attributed to the partner, which may impact on men's perception of relationship quality.

In the present study, which assessed responses to both negative and positive emotion, husbands and wives reported lower satisfaction when they (themselves) tended to bottle up positive emotion. These results fit with other empirical work highlighting the role of spouses' sharing of positive af- 
fect in maintaining relationship quality (Osgarby \& Halford, 1996).

In terms of results that were robust across gender, it seems that spouses are more satisfied with their marriage when they themselves express positive emotions, and when their partners express their negative emotions. These two associations probably involve quite different mechanisms. One's own expression of positive emotion may be linked with marital satisfaction because it reflects the positivity of one's dominant sentiment about the relationship ("sentiment override"; Weiss, 1980), and/or because it indicates a commitment to maintaining and nurturing the relationship. By contrast, partner's expression of negative emotion may be linked with satisfaction because the open expression of negative feelings allows potential relationship problems to be discussed, and hence resolved. This proposition is consistent with research showing that one partner's withdrawal from marital conflict leaves the other in a position of powerlessness, and that this pattern of dyadic communication is destructive (Christensen, 1988; Christensen \& Heavey, 1990; Heavey, Layne, \& Christensen, 1993).

Attachment and emotional control variables were roughly equal in importance as predictors of marital satisfaction. Measures of emotional control predicted substantial variance in satisfaction, after attachment variables were accounted for. Conversely, the attachment dimensions reliably predicted satisfaction, after emotional control was accounted for. In general, it appears that the effects of attachment and emotional control on satisfaction are largely independent, except for the effects of husbands' Comfort. The precise mechanisms underlying these effects require further research attention.

\section{Summary and Conclusions}

The results of this study indicate that insecure attachment was associated with less frequent and intense positive emotion and with more frequent and intense negative emotion, although these associations ap- plied primarily to emotions directly attributed to the spouse. Insecure attachment was also associated with greater control of emotion within the marriage. An important finding was that anxious/ambivalence did not appear to be linked with extreme expressions of distress. Rather, consistent with Bowlby's description of anxious attachment, adults who are anxious about loss and abandonment seem to try to inhibit the display of emotions that may alienate their partners, although these emotions may be leaked verbally and/or nonverbally.

The observed links between attachment dimensions and both emotional experience and emotional expression suggest that attachment plays a role in influencing the emotional climate of marriage, although the associations were generally not strong. This role applies to partner's attachment, as well as to own attachment. Further, consistent with a large body of literature, greater marital satisfaction was reported by those who described themselves as securely attached, and by those who reported more open expression of emotion by self and spouse.

Several of the links between attachment and emotional experience and expression depended on context (partner-related or not), attachment dimension, and gender. In addition, some links were specific to particular emotions (e.g., Anxiety was linked with the control of feelings of love involving the partner, but not of happiness or pride). Hence, researchers must recognize the complexity of the link between attachment style and responses to affect-laden relationship events. Overall, despite the fact that attachment researchers have focused on the regulation of negative affect, the present results highlight the need to study the experience and expression of both positive and negative emotions in marriage. The results would be strengthened by longitudinal studies assessing the implications of emotional experience and expression for the development and maintenance of intimate relationships, and by studies that include spouses' assessments of their partners' emotional experience and expression. 


\section{References}

Baron, R. M., \& Kenny, D. A. (1986). The moderatormediator variable distinction in social psychological research: Conceptual, strategic, and statistical considerations. Journal of Personality and Social Psychology, 51, 1173-1182.

Bartholomew, K., \& Horowitz, L. M. (1991). Attachment styles among young adults: A test of a fourcategory model. Journal of Personality and Social Psychology, 61, 226-244.

Belsky, J., Fish, M., \& Isabella, R. (1991). Continuity and discontinuity in infant negative and positive emotionality: Family antecedents and attachment consequences. Developmental Psychology, 27, 421431.

Bowlby, J. (1973). Attachment and loss: Vol. 2. Separation. New York: Basic Books.

Bradbury, T. N., \& Fincham, F. D. (1991). A contextual model for advancing the study of marriage. In $G$. J. O. Fletcher \& F. D. Fincham (Eds.), Cognition in close relationships (pp. 127-147). Hillsdale, NJ: Erlbaum.

Broderick, J. E., \& O'Leary, D. (1986). Contribution of affect, attitudes, and behavior to marital satisfaction. Journal of Consulting and Clinical Psychology, 54, 514-577.

Chance, M.R.A. (1980). An ethological assessment of emotion. In R. Plutchik \& H. Kellerman (Eds.), Emotion: Theory, research, and experience (pp. 81 111). New York: Academic Press.

Christensen, A. (1988). Dysfunctional interaction patterns in couples. In P. Noller \& M. A. Fitzpatrick (Eds.), Perspectives on marital interaction (pp. 31-52). Clevedon, England: Multilingual Matters.

Christensen, A., \& Heavey, C. L. (1990). Gender, power, and marital conflict. Journal of Personality and Social Psychology, 59, 73-85.

Collins, N.L., \& Read, S.J. (1990). Adult attachment, working models, and relationship quality in dating couples. Journal of Personality and Social Psychology, 58, 644-663.

Collins, N. L., \& Read, S. J. (1994). Cognitive representations of attachment: The structure and function of working models. In K. Bartholomew \& D. Perlman (Eds.), Advances in personal relationships: Vol. 5. Attachment processes in adulthood (pp. 5390). London: Jessica Kingsley.

Feeney, J. A. (1995). Adult attachment and emotional control. Personal Relationships, 2, 143-159.

Feeney, J. A. (1996). Attachment, caregiving, and marital satisfaction. Personal Relationships, 3, 401-416.

Feeney, J. A. (1998). Adult attachment and relationship-centered anxiety: Responses to physical and emotional distancing. In J. A. Simpson \& W. S. Rholes (Eds.), Attachment theory and close relationships (pp. 189-218). New York: Guilford Press.

Feeney, J. A., \& Noller, P. (1991). Attachment style and verbal descriptions of romantic partners. Journal of Social and Personal Relationships, 8, 187-215.

Feeney, J. A., \& Noller, P. (1992). Attachment style and romantic love: Relationship dissolution. Australian Journal of Psychology, 44, 69-74.

Feeney, J. A., \& Noller, P. (1996) Adult attachment. Thousand Oaks, CA: Sage.

Feeney, J. A., Noller, P., \& Callan, V. J. (1994). Attachment style, communication and satisfaction in the early years of marriage. In K. Bartholomew \& D. Perlman (Eds.), Advances in personal relationships: Vol. 5. Attachment processes in adulthood (pp. 269308). London: Jessica Kingsley.

Feeney, J. A., Noller, P., \& Roberts, N. (1998). Emotion, attachment, and satisfaction in close relationships. In P. A. Andersen \& L. K. Guerrero (Eds.), The handbook of communication and emotion ( $\mathrm{pp}$. 473-505). San Diego, CA: Academic Press.

Feeney, J. A., \& Ryan, S. M. (1994). Attachment style and affect regulation: Relationships with health behavior and family experiences of illness in a student sample. Health Psychology, 13, 334-345.

Fischer, K. W., \& Tangney, J. P. (1995). Self-conscious emotions and the affect revolution: Framework and overview. In J. P. Tangney \& K. W. Fischer (Eds.), Self-conscious emotions (pp. 3-22). New York: Guilford Press.

Fuller, T. L., \& Fincham, F. D. (1995). Attachment style in married couples: Relation to current marital functioning, stability over time, and method of assessment. Personal Relationships, 2, 17-34.

Hazan, C., \& Shaver, P. R. (1987). Romantic love conceptualized as an attachment process. Journal of Personality and Social Psychology, 52, 511-524.

Hazan, C., \& Shaver, P. R. (1994). Attachment as an organizational framework for research on close relationships. Psychological Inquiry, 5, 1-22.

Heavey, C. L., Layne, C., \& Christensen, A. (1993). Gender and conflict structure in marital interaction: A replication and extension. Journal of Consulting and Clinical Psychology, 61, 16-27.

Kirkpatrick, L. E., \& Davis, K. E. (1994). Attachment style, gender, and relationship stability: A longitudinal analysis. Journal of Personality and Social Psychology, 66, 502-512.

Kobak, R.R., \& Hazan, C. (1991). Attachment in marriage: Effects of security and accuracy of working models. Journal of Personality and Social Psychology, 60, 861-869.

Kobak, R. R., \& Sceery, A. (1988). Attachment in late adolescence: Working models, affect regulation, and representations of self and others. Child Development, 59, 135-146.

Mascolo, M.F., \& Fischer, K. W. (1995). Developmental transformations in appraisals for pride, shame, and guilt. In J. P. Tangney \& K. W. Fischer (Eds.), Selfconscious emotions (pp. 64-113). New York: Guilford Press.

Mikulincer, M., Florian, V., \& Tolmacz, R. (1990). Attachment styles and fear of personal death: A case study of affect regulation. Journal of Personality and Social Psychology, 58, 273-280.

Mikulincer, M., \& Nachshon (1991). Attachment styles and patterns of self-disclosure. Journal of Personality and Social Psychology, 61, 321-331.

Mikulincer, M., \& Orbach, I. (1995). Attachment styles and repressive defensiveness: The accessibility and architecture of affective memories. Journal of Personality and Social Psychology, 68, 917-925.

Noller, P., \& Fitzpatrick, M. A. (1990). Marital communication in the eighties. Journal of Marriage and the Family, 52, 832-843.

Noller, P., \& Gallois, C. (1988). Understanding and misunderstanding in marriage: Sex and marital ad- 
justment differences in structured and free interaction. In P. Noller \& M. A. Fitzpatrick (Eds.), Perspectives on marital interaction (pp. 53-77). Clevedon, England: Multilingual Matters.

Noller, P., Law, H., \& Comrey, A. L. (1987). Cattell, Comrey, and Eysenck personality factors compared: More evidence for the five robust factors? Journal of Personality and Social Psychology, 53, $775-782$.

Norton, R. (1983). Measuring marital quality: A critical look at the dependent variable. Journal of Marriage and the Family, 45, 141-151.

Osgarby, S. M., \& Halford, W. K. (1996). Being positive does matter: Behaviour, cognition, affect and physiology of couples during problem solving and positive reminiscence discussions. Manuscript in preparation, Psychiatry Department, University of Queensland.

Pistole, M. C. (1994). Adult attachment styles: Some thoughts on closeness-distance struggles. Family Process, 33, 147-159.

Shaver, P. R., \& Brennan, K. A. (1992). Attachment styles and the 'big five' personality traits: Their connections with each other and with romantic relationship outcomes. Personality and Social Psychology Bulletin, 18, 536-545.

Shaver, P. R., Morgan, H. J., \& Wu, S. (1996). Is love a "basic" emotion? Personal Relationships, 3, 81-96.

Simpson, J. A. (1990). Influence of attachment styles on romantic relationships. Journal of Personality and Social Psychology, 59, 971-980.
Simpson, J. A., Rholes, W. S., \& Nelligan, J. S. (1992). Support seeking and support giving within couples in an anxiety-provoking situation: The role of attachment styles. Journal of Personality and Social Psychology, 62, 434-446.

Simpson, J. A., Rholes, W. S., \& Phillips, D. (1996). Conflict in close relationships; An attachment perspective. Journal of Personality and Social Psychology, 71, 899-914.

Sroufe, L. A., \& Waters, E. (1977). Attachment as an organizational construct. Child Development, 48, 1184-1199.

Stipek, D. (1995). The development of pride and shame in toddlers. In J. P. Tangney \& K. W. Fischer (Eds.), Self-conscious emotions (pp. 237-252). New York: Guilford Press.

Strahan, B. J. (1991). Attachment theory and family functioning: Expectations and congruencies. Australian Journal of Marriage and Family, 12, 12-26.

Wallbott, H. G., \& Scherer, K. R. (1988). How universal and specific is emotional experience? In K. R. Scherer (Ed.), Facets of emotion (pp. 31-56). Hillsdale, NJ: Erlbaum.

Watson, M., \& Greer, S. (1983). Development of a questionnaire measure of emotional control. Journal of Psychosomatic Research, 27, 299-305.

Weiss, R. L. (1980). Strategic behavioral marital therapy: Toward a model for assessment and intervention. In J. P. Vincent (Ed.), Advances in family intervention, assessment and theory (Vol.1,pp. 229-271). Greenwich, CT: JAI Press. 